\section{Debut of Polyglandular Autoimmune Syndrome Type 2 (Schmidt Syndrome) in a Patient with Chronic Kidney Disease of Unknown Etiology in Peritoneal Dialysis}

\author{
lyad Abuward Abu-Sharkh*, Igor Romaniouk Jakovler, \\ Suleyka Puello Martinez, Manuel Fidalgo Díaz, Nisrine Arhda, \\ Marta Pais Seijas and Candido Díaz Rodriguez
}

Department of Nephrology, University Clinical Hospital of Santiago de Compostela, Spain

\begin{abstract}
Schmidt Syndrome refers to the combination of autoimmune adrenal insufficiency (Addison's disease) with autoinmune thyroiditis, and is part of a larger syndrome known as autoinmune polyendocrine syndrome type II or polyglandular autoinmune syndrome type II (PAS II). Schmidt Syndrome as a 1:20,000 prevalence in general population with $3: 1$ ratio of females to males affected. It is autosomal dominant inheritance with variable penetrance. Associated with certain HLA antigens HLA-DR3, HLA-DR4, non HLA gene M-ICA and CTLA-4. The diagnosis of the Schmidt Syndrome is the same as that of the individual disorders. The treatment includes of primary
\end{abstract}

*Corresponding author: lyad Abuward Abu-Sharkh, Nephrology Department, University Clinical Hospital of Santiago de Compostela, Spain, Tel: +34639021641; E-mail: eyadward@hotmail.com

Citation: Abuward Abu-sharkh I, Jakovler IR, Martinez SP, Díaz MF, Arhda N et al. (2018) Debut of Polyglandular Autoimmune Syndrome Type 2 (Schmidt Syndrome) in a Patient with Chronic Kidney Disease of Unknown Etiology in Peritoneal Dialysis. J Nephrol Renal Ther 4: 019.

Received: August 03, 2018; Accepted: November 06, 2018; Published: November 21, 2018

Copyright: @ 2018 Abuward Abu-sharkh I, et al. This is an open-access article distributed under the terms of the Creative Commons Attribution License, which permits unrestricted use, distribution, and reproduction in any medium, provided the original author and source are credited. hypothyroidism and the Addison disease. We present the evolution, the clinic and the treatment of a patient diagnosed with Schmidt Syndrome.

Keywords: Addison disease; Hashimoto's thyroiditis; Peritonea dialysis; Polyglandular autoimmune syndrome; Schmidt Syndrome

\section{Introduction}

Autoimmune polyglandular syndrome is a rare disease, that is defined by the presence of two or more glandular insufficiencies caused by autoimmune mechanisms and that may be associated with other pathologies and immunological phenomena. It is characterized by the presence of circulating organospecific antibodies and lymphocytic infiltration of the affected gland. It is classified into 4 types. Polyglandular syndrome type 2 (Schmidt Syndrome) includes adrenal insufficiency associated with autoimmune thyroid disease or type 1 diabetes mellitus [1-3].

A 36-year-old woman with end-stage renal disease of unknown etiology in long-standing peritoneal dialysis who went to the emergency room for marked arterial hypotension and was subsequently diagnosed with autoimmune polyglandular syndrome. We present the evolution, the clinic and the treatment of the syndrome.

\section{Case Report}

A 36-year-old patient with the following background: end-stage renal failure in the peritoneal dialysis program since March 2010, diagnosed in 2009 with autoimmune thyroid disease with fine needle aspiration suggestive of Hashimoto's thyroiditis and presence of anti-TPO antibodies in blood. In September 2014, a total parathyroidectomy and bilateral total thyroidectomy was done. After the biopsy was made, she was diagnosed with classic multifocal papillary carcinoma and confirming lymphocytic thyroiditis. The patient was treated by the endocrinology service with iodine 131 without incidents. In February 2016 she went to the emergency department for presenting vomiting and dizziness, upon arrival the physical examination was: blood pressure $60 / 40 \mathrm{mmHg}$, skin pallor, analytically: leukocytes 5400 (400010000), eosinophils $8 \%(0.5-6)$, hemoglobin $12.7 \mathrm{~g} / \mathrm{dl}$ (12-16), hematocrit 37.6\% (37-49), platelets 224,000(138000-381000), albumin $3 \mathrm{mg} / \mathrm{dl}$ (4-5.2), glucose $95 \mathrm{mg} / \mathrm{dl}$ (74-105), urea $52 \mathrm{mg} / \mathrm{dl}$ (13-50), uric acid $3.6 \mathrm{mg} / \mathrm{dl}$ (2.4-6.4) potassium $3.6 \mathrm{mEq} / \mathrm{L}(3.6-4.9)$, lactic dehydrogenase $249 \mathrm{IU} / \mathrm{ml}$ (200-418), Sodium 127 mEq / L(137-148) thyrotropin stimulating hormone $13.68 \mathrm{mUI} / \mathrm{L}(0.35-5.5)$, T4 1.45 $\mathrm{ng} / \mathrm{dl}(0.89-1.76)$, parathyroid $32 \mathrm{pg} / \mathrm{ml}(10-55)$, cortisol $2.3 \mu \mathrm{g} / \mathrm{dl}$ (5.27-22.45), protein $\mathrm{C}$ reagent $0.4 \mathrm{mg} / \mathrm{dl}$, negative tumor markers, autoimmunity was negative.

The patient received the following peritoneal dialysis pattern: 3 exchanges of $2000 \mathrm{cc}$ with physioneal 35 to $1.36 \%$, and negative balances of $-700-800 \mathrm{ml} /$ day. An echocardiogram was performed with the following findings: undilated cardiac chambers. Hyperdynamic left ventricular function. Chest radiology: rule out acute pathology. Abdominal ultrasound: kidneys of small size $6 \mathrm{~cm}$, difficult to delimit, intra-abdominal fluid in relation to peritoneal dialysis. 
Under suspicion of an undiagnosed adrenal insufficiency syndrome, ACTH, cortisol, aldosterone and anti-alpha 21 hydroxylase levels were requested, these being negative important elevation of ACTH $(1812 \mathrm{pg} / \mathrm{ml})$ and a low cortisol $(2.3 \mu \mathrm{g} / \mathrm{dl})$. A Synacthen test was done and it was positive, with a clear absence of elevation pf plasma cortisol. Water replacement is performed, treatment is initiated Fludrocortisone 0.1/day and Hydrocortisone $50 \mathrm{mg} / 8$ hour, gradually improving the patient, and being discharged home at home with maintenance treatment 7 days later after stabilization. Subsequently, the immunological study reflects the presence of positive anti-adrenal antibodies being diagnosed the patient of autoimmune adrenal insufficiency, diabetes mellitus was ruled out, Anti GAD/64k, Anti-IA, and Anti insulin antibodies were negative. Two sisters of the patient, aged 32 and 40, were studied and were positive with anti-TPO antibodies, one of them asymptomatic and the other with clinical hypothyroidism.

\section{Discussion}

Autoimmune polyglandular syndrome is a rare disorder of autoimmune etiology that affects two or more glands and that may be associated with more disorders of autoimmune origin. It is characterized by immunological phenomena that cause the loss of self-tolerance to the target organ, thus inducing the formation of circulating organospecific antibodies that subsequently and in the presence of glandular lymphocytic infiltrate causes destruction of the glandular parenchyma causing failure of the affected organ. The polyglandular syndrome (autoimmune polyendocrinopathy) has been classified into 4 types (Table 1):

Type 1: Also known as APECED (Autoimmune Polyendocrinopathy, Candidiasis and Ectodermal dystrophy) a very rare entity, as a very low incidence $1 / 80000$, and a very variable prevalence, is more frequent in populations with a high degree of consanguinity [3]. It has an autosomal recessive pattern of inheritance and is associated with the mutation of the AIRE autoimmune regulatory gene [4], located on chromosome 21q22.3. Its main components are mucocutaneous candidiasis, adrenal insufficiency and hypoparathyroidism, for its diagnosis the syndrome must have at least two of its main components, it can also be associated with other autoimmune disorders such as gonadal insufficiency, vitiligo, and celiac disease alopecia among others. Its main components usually appear at 3-5 years and before 20 years.

Type 2: It is the most frequent of the polyglandular syndromes, affects more women 3:1, and as a prevalence of 2-4.5: 100000 inhabitants. Appears in adulthood from 3-4 decade of life, is of autosomal dominant inheritance with incomplete penetrance, it is believed that there is a polygenic predisposition of chromosome 6 . In some studies has been a relationship between the appearance of the disease and the presence of alleles B8 and DR3 of HLA and in adrenal insufficiency with DR3 and DR4. This makes it necessary to rule out involvement in first-degree relatives [5]. Its main components are, involvement of the adrenal gland and thyroid gland (Schmidt Syndrome) or the adrenal gland and pancreas (carpenter syndrome) may be associated with other effects of other organs such as gonadal failure, myasthenia, celiac disease $[6,7]$.

Type 3: It is the association of thyroid disease with other autoimmune diseases that affect other organs where the adrenal is not found, depending on the affected organs it is classified in / 3A (thyroid + DM1) 3B (thyroid + gastrointestinal diseases), 3B (Thyroid + skin diseases) and 3D (thyroid + collagen diseases) all of autoimmune etiopathogenesis, as a poorly defined inheritance pattern, but seems to be dominant. It appears in adults and is very rare presentation [8].

\begin{tabular}{|c|c|c|c|}
\hline Polyglandular Autoimmune Syndrome 2 & $\begin{array}{ll}\cdot & \text { Addison disease } \\
\cdot & \text { Thyroid disease } \\
\cdot & \text { Autoimmune } \\
\text { - } & \text { Mellitus diabetes }\end{array}$ & $\begin{array}{l}\text { Vitiligo Atrophic Gastritis Autoim- } \\
\text { mune Hepatitis Pernicious Anemia } \\
\text { Hypogonadism Alopecia Myasthenia } \\
\text { gravis }\end{array}$ & Adolescence and adults \\
\hline Polyglandular Autoimmune Syndrome 3 & $\begin{array}{l}\text { 3A (thyroid + DM1) 3B (thyroid + gastrointes- } \\
\text { tinal diseases), 3B (Thyroid + skin diseases) } \\
\text { and 3D (thyroid + collagen diseases) }\end{array}$ & Other endocrine affection & Adults \\
\hline
\end{tabular}

Table 1: Differences between polyglandular syndromes. 
Type 4: Encompasses endocrine diseases that do not appear in previous classifications such as (adrenal involvement + hypogonadism), is rare and appears in adults, and remains poorly defined genetic patron [9].

Recall that adrenal glands are divided both anatomically and functionally into two parts: cortex and medulla. In turn, the cortex is subdivided into three zones: glomeruli, produced mainly by aldosterone, the main mineral-corticoid, which contributes to the electrolyte balance through the homeostasis of sodium and potassium. The fasciculate zone is responsible for the synthesis of glucocorticoids, such as cortisol, which affects glucose metabolism and normal cellular function [10].

With the destruction of the gland, on the one hand, low levels of cortisone stimulate ACTH-CRH, increasing levels of ACTH causing hyper pigmentation. On the other hand, the deficit of cortisol decreases gluconeogenesis, producing hypoglycemia, asthenia and muscular fatigability. As the glomerular zone is destroyed, plasma renin levels and angiotensin II, increase to maintain a normal aldosterone secretion, until finally there is a deficit in mineralocorticoid secretion [11]. The treatment is hormone replacement, and sympthoms treatment [12].

\section{Conclusion}

Autoimmune polyglandular syndrome is a rare disorder of autoimmune etiology that affects two or more glands and that may be associated with more disorders of autoimmune origin. Appears in adulthood from 3-4 decade of life with involvement of the thyroid gland. Its long latent period, is mainly due to the maintenance of the function of the adrenal glands, however, once marked destruction of these occurs, symptoms such as nausea, dizziness, often symptoms that are confused with a perennial picture treated many sometimes with volume repletion. However, sustained hypoglycemia, arterial hypotension and coloration of skin should raise suspicion of a pathology that has not yet been diagnosed. Early detection is considered essential to avoid major complications. The level of $\mathrm{ACTH}$, aldosterone and imaging tests provide valuable data about the disease.

\section{Disclosure of Potential Conflicts of Interest}

The authors declare that there is no conflict of interests.

\section{Research Involving Human Participants and/or Animals}

The authors declare that there was no research involving human and/or animal participants.

\section{References}

1. Garrido MJM, Ponce CG, Risueño MG, Mora A, Carrato A (2007) Syndrome pluriglandular autoinmune: Revisión. An Med Interna (Madrid, Spain) 24: 445-452.

2. Betterle C, Zanchetta R (2003) Update on autoimmune polyendocrine syndromes (APS). Acta Biomed Ateneo 74: 9-33.

3. Bahceci M, Tuzcu A, Pasa S, Ayyildiz D, Tuzcu S (2004) Polyglandular autoimmune syndrome type III accompanied by common variable immunodeficiency. Gynecol Endocrinol 19: 47-50.

4. Esselborn VM, Landing BH, Whitaker J, Williams RR (1956) The syndrome of familial juvenile hypoadrenocorticism, hypoparathyroidism and superficial moniliasis. J Clin Endocrinol Metab 16: 1374-1387.

5. Partanen J, Peterson P, Westman P, Aranko S, Krohn K (1994) Major histocompatibility complex class II and III in Addison's disease. MHC alleles do not predict autoantibody specificity and 21-hydroxylase gene polymorphism has no independent role in disease susceptibility. Hum Immunol 41: $135-140$

6. Zlotogora J, Shapiro MS (1992) Polyglandular autoimmune syndrome type I among Iranian Jews. J Med Genet 29: 824-826.

7. Muir A, She JX (1999) Advances in the genetics and immunology of autoimmune polyglandular syndrome II/III and their clinical applications. Ann Med Interne 150: 301-312.

8. Michels AW, Eisenbarth GS (2010) Inmunologic Endocrine Disorders. J Allergy ClinImmunol 125: 226-237.

9. Eisenbarth GS, Gottlieb PA (2004) Autoimmune Polyendocrine Syndromes. N Engl J Med 350: 2068-2079.

10. Schrier RW (2006) Body water homeostasis: Clinical disorders of urinary dilution and concentration. J Am Soc Nephrol 17: 1820-1832.

11. Sachdev Y, Morley AR, Wilkinson R, Hall R (1977) Addison's disease with renal microangiopathy and renal failure. Q J Med 182: 151-162.

12. Siddiqi SS, Singh SK, Khan SA, Ishtiaq O, Pathan MF, et al. (2012) Guidelines regarding management of adrenal insufciency in the Holy month of Ramadan. Indian J Endocrinol Metab 16: 519-521. 


\section{di}

Journal of Anesthesia \& Clinical Care

Journal of Addiction \& Addictive Disorders

Advances in Microbiology Research

Advances in Industrial Biotechnology

Journal of Agronomy \& Agricultural Science

Journal of AIDS Clinical Research \& STDs

Journal of Alcoholism, Drug Abuse \& Substance Dependence

Journal of Allergy Disorders \& Therapy

Journal of Alternative, Complementary \& Integrative Medicine

Journal of Alzheimer's \& Neurodegenerative Diseases

Journal of Angiology \& Vascular Surgery

Journal of Animal Research \& Veterinary Science

Archives of Zoological Studies

Archives of Urology

Journal of Atmospheric \& Earth-Sciences

Journal of Aquaculture \& Fisheries

Journal of Biotech Research \& Biochemistry

Journal of Brain \& Neuroscience Research

Journal of Cancer Biology \& Treatment

Journal of Cardiology \& Neurocardiovascular Diseases

Journal of Cell Biology \& Cell Metabolism

Journal of Clinical Dermatology \& Therapy

Journal of Clinical Immunology \& Immunotherapy

Journal of Clinical Studies \& Medical Case Reports

Journal of Community Medicine \& Public Health Care

Current Trends: Medical \& Biological Engineering

Journal of Cytology \& Tissue Biology

Journal of Dentistry: Oral Health \& Cosmesis

Journal of Diabetes \& Metabolic Disorders

Journal of Dairy Research \& Technology

Journal of Emergency Medicine Trauma \& Surgical Care

Journal of Environmental Science: Current Research

Journal of Food Science \& Nutrition

Journal of Forensic, Legal \& Investigative Sciences

Journal of Gastroenterology \& Hepatology Research
Journal of Gerontology \& Geriatric Medicine

Journal of Genetics \& Genomic Sciences

Journal of Hematology, Blood Transfusion \& Disorders

Journal of Human Endocrinology

Journal of Hospice \& Palliative Medical Care

Journal of Internal Medicine \& Primary Healthcare

Journal of Infectious \& Non Infectious Diseases

Journal of Light \& Laser: Current Trends

Journal of Modern Chemical Sciences

Journal of Medicine: Study \& Research

Journal of Nanotechnology: Nanomedicine \& Nanobiotechnology

Journal of Neonatology \& Clinical Pediatrics

Journal of Nephrology \& Renal Therapy

Journal of Non Invasive Vascular Investigation

Journal of Nuclear Medicine, Radiology \& Radiation Therapy

Journal of Obesity \& Weight Loss

Journal of Orthopedic Research \& Physiotherapy

Journal of Otolaryngology, Head \& Neck Surgery

Journal of Protein Research \& Bioinformatics

Journal of Pathology Clinical \& Medical Research

Journal of Pharmacology, Pharmaceutics \& Pharmacovigilance

Journal of Physical Medicine, Rehabilitation \& Disabilities

Journal of Plant Science: Current Research

Journal of Psychiatry, Depression \& Anxiety

Journal of Pulmonary Medicine \& Respiratory Research

Journal of Practical \& Professional Nursing

Journal of Reproductive Medicine, Gynaecology \& Obstetrics

Journal of Stem Cells Research, Development \& Therapy

Journal of Surgery: Current Trends \& Innovations

Journal of Toxicology: Current Research

Journal of Translational Science and Research

Trends in Anatomy \& Physiology

Journal of Vaccines Research \& Vaccination

Journal of Virology \& Antivirals

Submit Your Manuscript: http://www.heraldopenaccess.us/Online-Submission.php 